\title{
PICU Follow Up- The Impact of Missed School Following Critical Illness
}

\author{
Kathleen Kastner*1, Neethi Pinto ${ }^{2}$, Michael E Msall ${ }^{3}$ and Sarah Sobotka ${ }^{4}$ \\ ${ }^{1}$ Assistant Professor of Pediatrics Division of Neurodevelopmental-Behavioral Pediatrics, University of Wisconsin School of Medicine and Public Health, \\ USA \\ ${ }^{2}$ Associate Professor of Pediatrics, Section of Pediatric Critical Care, The University of Chicago, USA \\ ${ }^{3}$ Professor of Pediatrics, Section of Developmental and Behavioral Pediatrics, Kennedy Research Center on Intellectual and Developmental Disabilities, \\ University of Chicago, USA \\ ${ }^{4}$ Assistant Professor Pediatrics, Section of Developmental and Behavioral Pediatrics, University of Chicago, USA
}

Submission: December 14, 2018; Published: January 04, 2019

*Corresponding author: Kathleen Kastner, MD, Assistant Professor of Pediatrics, Division of Neurodevelopmental-Behavioral Pediatrics, University of Wisconsin School of Medicine and Public Health, 1500 Highland Avenue, Rm. 345, Madison, WI 53705, USA

Abstract

There can be significant morbidity for children following PICU admission. The impact that PICU admission has on school attendance and performance may be the source of some of the sequelae of critical illness. However, current supports are limited for addressing these needs. Families report inadequate support from schools and worsening academic performance after critical illness. The transition back to school can be challenging. Additional studies are needed to develop proactive supports, such as PICU follow up programs, to improve the care of children following critical illness.

Keywords: PICU; Follow-up; Family Support; School; Discharge

\section{Opinion}

Although mortality related to pediatric critical illness has decreased, morbidity among pediatric intensive care unit (PICU) survivors has increased [1]. Therefore, there is an urgent need to understand and reduce the long-term morbidity of these survivors and optimize their school and community functioning. Studies show that admission to the PICU may have a significant impact on both the neuropsychological functioning of children and their health-related quality of life (HRQOL). For example, children who survive critical illness experience increased emotional difficulties, perform worse on tests of intelligence, executive function, and memory, and are perceived by their teachers as having more educational problems than children without a history of critical illness [2-4]. When compared to healthy children, critically ill children have lower HRQOL [5-7] and experience a significant decrease in HRQOL after PICU admission [3]. PICU survivors are also at increased risk of psychological sequelae including behavioral changes, fatigue disorders, and sleep disturbances, 4,8 and symptoms of post-traumatic stress disorders (PTSD) $[4,9]$. Higher levels of parental distress, longer PICU stays, and emergency admissions are associated with increased likelihood of PTSD among PICU survivors.8 Despite this growing body of evidence, there is no standard of care for follow up of children after discharge from the PICU. Though other critical care environments, such as the neonatal intensive care unit, have implemented standardized follow up programs to address sequelae of critical illness and ensure a smooth transition following discharge, there is often a lack of such support for children who are discharged from the PICU. The development of evidence-based programs for PICU follow up are needed to decrease post-discharge complications and to improve child and family resiliency after PICU admission.

Several factors may influence post-discharge outcomes following PICU admission, including underlying health status and co-morbidities, diagnosis/reason for admission, and length of stay (LOS) [3,10-13]. However, there may be other factors which are modifiable post-discharge. Such factors could therefore be addressed by care in a PICU follow up program in order to further improve outcomes for children even after they have been discharged. One potential mediator of long-term outcomes for PICU survivors is the role of missed school. Because school shapes a child's social, cognitive, language, behavioral, and physical development, school absences and difficulties with school re-integration, in part, may account for the negative sequelae associated with critical illness. In addition, there are high rates of neurodevelopmental disabilities among children admitted to the PICU [14], which may further increase the risk for poor outcomes with missed school. However, there have been few published studies of the impact of PICU admission on school attendance and performance. We completed a pilot study to explore the extent to which PICU admission dis- 
rupts school attendance and school performance and to describe the supports and barriers children and their families experience with regard to school re-integration. In our pilot cohort of children admitted to the PICU at an urban academic medical center $(n=21)$, we found that nearly half of children missed seven or more days for critical illness, and among those children, over half did not receive any tutoring or homebound services. In accordance with the AAP policy statement, Home, Hospital, and Other Non-School Based Instruction for Children and Adolescents Who Are Medically Unable to Attend School [15], because any school absence is disruptive to the educational process, a request for non-school based instruction should be considered in a timely manner. The recommendation for implementation of robust homebound educational services for children who are unable to attend school due to medical illness implicitly recognizes the importance of attention to school disruption [15]. However, there are suboptimal resources and fragmented pathways for implementing these services. In our pilot study, twenty percent of parents reported that schools do not adequately address school reintegration, and sixty-seven percent of parents reported that their health care provider did not discuss the child's return to school. If discussion of school reintegration between physicians and parents was standard practice prior to and after PICU discharge, we may be better able to anticipate school-related learning challenges and proactively support patients in this transition.

To determine how to best support children with critical illness, we may look to existing models and lessons learned from pediatric populations with cancer. Support models for children with cancer returning to school have described a number of different approaches during school re-integration [16-18], In a qualitative study, teachers, parents, and children with cancer consistently reported a comprehensive school-based reintegration program was beneficial in facilitating school re-entry. The intervention included interim educational services during hospitalization, identification of a liaison between the hospital and school, psychoeducation for the child and parents prior to school re-entry, presentations for school personnel and peers about the child's illness, and periodic follow-up with all involved parties to address any problems that arose.16 Another study described a similar school re-integration model which utilized a school-hospital liaison team that coordinated communication among all parties, provided counseling support to the child, their family, school personnel, and peers, and facilitated ongoing follow-up [18].

We recognize that there may potentially be significant logistical and financial barriers which would limit the feasibility of such a program for all children who have been admitted to the PICU. Therefore, it may be most effective to target efforts to the patient populations which are most likely to require support during the transition from PICU (or hospital) to home, such as those with prolonged hospitalizations and significant morbidity following critical illness. In our pilot study, we found that parents whose child had a length of stay of seven days or longer universally completed telephone follow-up at three months, whereas only half of those with a shorter stay completed telephone follow up. Perhaps those families with a longer length of stay are more likely to need and seek support after their child's discharge and therefore were open to participating in our study of PICU follow-up academic needs. We note that discussion of school reintegration may be difficult in the primary care setting due to time constraints; a PICU survivor may necessitate a high level of medical care complexity, and at times there is a lack of consistent communication between inpatient providers and ambulatory providers. This presents an opportunity for inpatient and ambulatory health care providers (pediatric intensivists, subspecialists, and primary care providers) to provide comprehensive care (e.g. (monitoring for medical complications, neurocognitive or neuropsychological evaluations, need for individualized education plan development, etc.) in a multidisciplinary setting such as PICU follow-up clinic. That venue could bring together experts in critical care, neurodevelopment, psychology, physiatry, and general pediatrics in order to coordinate complex care for these medically vulnerable children and their families.

\section{Conclusion}

In summary, there is a robust body of evidence that critically ill children experience significant disruptions in functioning after discharge. This impact on functioning is likely multifactorial in origin, including medical complications, missed school, and psychological stressors. Despite the existence of standard follow up programs for neonate survivors of critical care, supports are currently inadequate for older children who experience a critical illness. Improved communication and coordination of care between multidisciplinary health care providers (intensivists, subspecialists, and primary care provider) proximal to a child's discharge from the PICU, with attention to the need to proactively address transition and re-integration to school, may benefit children who experience critical illness. Future research is needed to assess the necessary components of such models as well as to further explore the other aspects of community re-integration that are challenging for families following their discharge from the PICU.

\section{References}

1. Pollack MM, Holubkov R, Funai T, Clark A, Berger JT, et al. (2014) Pediatric intensive care outcomes: development of new morbidities during pediatric critical care. Pediatr Crit Care Med 15(9): 821-827.

2. Als LC, Nadel S, Cooper M, Pierce CM, Sahakian BJ, et al. (2013) Neuropsychologic function three to six months following admission to the PICU with meningoencephalitis, sepsis, and other disorders: a prospective study of school-aged children. Crit Care Med 41(4): 10941103.

3. Polic B, Mestrovic J, Markic J, Mestrovic M, Capkun V, et al. (2013) Long-term quality of life of patients treated in paediatric intensive care unit. Eur J Pediatr 172(1): 85-90.

4. Als LC, Picouto MD, Hau SM, Nadel S, Cooper M, et al. ( 2015) Mental and physical well-being following admission to pediatric intensive care. Pediatr Crit Care Med. 2015;16(5): e141-e149.

5. Knoester H, Bronner MB, Bos AP, Grootenhuis MA ( 2008) Quality of life in children three and nine months after discharge from a paediatric intensive care unit: a prospective cohort study. Health Qual Life Outcomes 6: 21. 
6. Colville GA, Pierce CM (2013) Children's self-reported quality of life after intensive care treatment. Pediatr Crit Care Med 14(2): e85-e92.

7. Ebrahim S, Singh S, Hutchison JS, Kulkarni AV, Sananes R, et al. (2013) Adaptive behavior, functional outcomes, and quality of life outcomes of children requiring urgent ICU admission. Pediatr Crit Care Med 14(1) 10-18.

8. Rennick JE, Rashotte J (2009) Psychological outcomes in children following pediatric intensive care unit hospitalization: a systematic review of the research. J Child Health Care 13(2): 128-149.

9. Rees G, Gledhill J, Garralda ME, Nadel S (2004) Psychiatric outcome following paediatric intensive care unit (PICU) admission: a cohort study. Intensive Care Med 30(8):1607-1614.

10. Mestrovic J, Kardum G, Sustic A, Polic B, Mestrovic M, et al. (2007) Neurodevelopmental disabilities and quality of life after intensive care treatment. J Paediatr Child Health43(10): 673-676.

11. Morrison AL, Gillis J, O'Connell AJ, Schell DN, Dossetor DR, et al. (2002) Quality of life of survivors of pediatric intensive care. Pediatr Crit Care Med 3(1): 1-5.

12. Fiser DH, Tilford JM, Roberson PK (2000) Relationship of illness severity and length of stay to functional outcomes in the pediatric intensive care unit: a multi-institutional study. Crit Care Med 28(4):1173-1179.
13. Newburger JW, Wypij D, Bellinger DC, du Plessis AJ, Kuban KC, et al. (2003) Length of stay after infant heart surgery is related to cognitive outcome at age 8 years. J Pediatr 143(1): 67-73.

14. Sobotka SA, Peters S, Pinto NP (2018) Neurodevelopmental Disorders in the PICU Population. Clin Pediatr (Phila) 57(8): 913-919.

15. American Academy of Pediatrics (2000) Committee on School Health. Home, hospital, and other non-school-based instruction for children and adolescents who are medically unable to attend school. Pediatrics 106(5): C1154-C1155.

16. Katz ER, Varni JW, Rubenstein CL, Blew A, Hubert N (1992) Teacher, parent, and child evaluative ratings of a school reintegration intervention for children with newly diagnosed cancer. Child Health Care. 21(2): 69-75.

17. Prevatt FF, Heffer RW, Lowe PA (2000) A review of school reintegration programs for children with cancer. J School Psychol. 2000;38(5):447467.

18. Worchel-Prevatt FF, Heffer RW, Prevatt BC, Jennifer Minera, Tammi Young-Saleme, et al. (1998) A school reentry program for chronically ill children. J School Psychol 36(3): 261-279.

\section{Your next submission with Juniper Publishers will reach you the below assets}

- Quality Editorial service

- Swift Peer Review

- Reprints availability

- E-prints Service

- Manuscript Podcast for convenient understanding

- Global attainment for your research

- Manuscript accessibility in different formats

( Pdf, E-pub, Full Text, Audio)

- Unceasing customer service

Track the below URL for one-step submission

https://juniperpublishers.com/online-submission.php 